\title{
Discussion on Customer Experience Model of B2C E-commerce Logistics Enterprises Based on TAM Model
}

\author{
Yilei Pei ${ }^{1,}$ a , Wanxin Xue ${ }^{1, b}$, Dandan $\mathrm{Li}^{1, c}$, Yong $\mathrm{Su}^{2, \mathrm{~d}}$ \\ ${ }^{1}$ Department of Information Management and E-commerce, Beijing Union University, Beijing, \\ 100101, China \\ ${ }^{2} 95997$ Unit of PLA, Beijing, 100076, China \\ aemail: peiyilei@126.com, bemail:xuewanxin@126.com, lidandanhdj@163.com, \\ dsudoo@163.com
}

Keywords: B2C e-commerce logistics enterprises; customer experience; the TAM model

\begin{abstract}
The service of E-Commerce logistics enterprises in our country is unable to meet the needs of consumers. The good customer experience can promote consumer s ' perception of the service level of E-Commerce logistics enterprises. The paper elaborates the factors affecting customer experience from website usefulness, website ease of use, transaction costs, customer participation and interactivity, Internet word of mouth five aspects combined with previous research literatures; establishes customer experience model of B2C e-commerce logistics enterprises based on the TAM model and points out the directions for future research.
\end{abstract}

\section{Introduction}

With the rapid development of Internet technology and e-commerce, more and more customers complete the purchasing, ordering, and even after-sales service of goods through the network. However, e-commerce logistics service is directly completed difficultly through the network, which affects the customer's perception of the overall service level of e-commerce. At present, China's e-commerce logistics services are mainly labor-intensive services and the utilization of basic facilities is low, so it is difficult to meet the growing demand for online consumers. Therefore, China's e-commerce logistics enterprises need to improve the service level of the distribution link of physical commodities urgently.

When customers make the purchase decision, they attach importance to obtaining the special feeling in accordance with the personality, taste preferences and values in the process of information collection and evaluation, namely the experience. E-Commerce customer experience is the process in which customers obtain the special feeling, form cognition and evaluation, thus affect the meeting of psychological demands and decision making through a set of shopping conditions and environments and interactive service that E-Commerce websites and operators provide. Customer experience becomes an important factor affecting consumers' online shopping behaviors, and good customer experience can promote consumers' web-based purchase behaviors.

Although customer experience is the important factor to promote purchase behaviors, but under the environment of E-Commerce customer experience has not been fully studied (Hsuan, 2011) [1], so the research on influencing factors of customer experience for B2C E-Commerce logistics enterprises is very important. The existing researches are done from the perspectives of website characteristics or customer characteristics. This paper collates all the research results, analyzes influencing factors of customer experience for B2C E-Commerce logistics enterprises, and establishes the model of customer experience for B2C E-Commerce logistics enterprises, to help enterprises understand and predict consumers' online shopping intention better.

\section{Review of Literature}

\section{Effects of Website Characteristics on Customer Experience}

Scholars study customer experience from the perspective of components of E-Commerce 
website characteristics. Madu (2002) proposes website characteristics include tangibility, reliability, responsiveness, assurance and empathy [2]. Jaeki (2012) thinks that website layout, the ability to select different payment means, the ability to check purchased product effectiveness, the ability to view previous orders, the ability to track orders and the ability to store and manage personal information will affect the availability of website and customer experience [3]. Shi Lulu (2013) puts forward online store image can create customer value. Online shops with excellent website navigation, rational website layout, and minimizing commodity displaying error can make customers visually excited, and enhance customers' pre-sales shopping experience to a certain extent [4]. Cao Yuanyuan (2013) identifies website navigation function, search function, operational flexibility, simplicity of operational process and other functions, and aesthetics, professionality, characteristics of website design affect customer experience [5].

\section{Effects of Internet Word of Mouth on Customer Experience}

Li Wei (2013) puts forward customers get indirect experience through customer evaluation of websites. Word of mouth is more convincing than advertising and business promotion, in a variety of information sources, in addition to customers' direct using experience, the shopping and using experience from other buyers is the most valuable indirect experience which helps customers who want to purchase complete certain experience [6]. Shi Lulu (2013) proposes Internet word of mouth has more persuasive effect on customer attitudes and purchasing behaviors than traditional word of mouth, and establishing the evaluation system of products is an important way to improve customers' pre-sales experience [4].

\section{Effects of Customer Participation on Customer Experience}

Rodiear (2000) puts forward customer participation refers to activities or resources customers provide in the process of service production or delivery, including mental, physical and even emotional pay, and it is customers' pay to meet individual needs and enjoy services [7]. Hsuan (2011)'s study shows customer participation in the blog affects customer experience and purchase intentions [8]. Wang Li (2007)'s study finds, the higher the degree of customer participation is, the more satisfying products the enterprise can design for customers, which can enhance customer experience [9].

\section{Effects of Network Transaction Cost on Customer Experience}

Xue Jun (2005) puts forward network transaction costs refer to the total costs consumers pay for purchased equipments, knowledge learning, information search, time, money and the risk borne, in order to complete network transaction [10]. Liu (2008) believes that transaction costs are decisive factors affecting customer's online shopping intention, and analyzes the impact of transaction cost on customer decision from the perspective of the qualitative study [11]. Zheng Lifeng(2009) reveals that transaction costs have a negative effect on customer's online purchase intention through the empirical research [12] .

\section{Customer Experience Model of B2C E-commerce Logistics Enterprises}

\section{The Model of User Behavior in the network environment}

In existing literatures, the theory of reasoned action (TRA) and the technology acceptance model (TAM) have been widely used for studying user behavior models in the field of information technology.

Fishbei (1975) propose TRA by describing the conscious behaviors according to the theory of social psychology [13]. The theory is that individuals' actual behaviors are determined by behavioral intention; and individuals' behavior intentions are subjected to behavior attitudes and subjective norms concerning external behaviors.

Davis (1989) proposes TRA on the basis of TAM [14]. This model is mainly used for analyzing and interpreting individuals' acceptance behaviors for information technology. Perceived usefulness and ease of use affect using attitude; perceived usefulness and using attitude affect behavior intention, and then affect the usage of the system. Zhang Nan (2007) puts forward as long as the appropriate expansion and modification of TAM, people can find and explain users' adoption process for the new technology very well, predict and explain users' behaviors to some 
extent [15]. Guo Hongli (2013) build B2C customer experience model based on the TAM model. There are website characteristics, customer characteristics and interaction three dimensions in the model. The three dimensions interact with one another and have a direct impact on customer experience. Customer experience determines customer purchasing intention finally, and then affects purchasing behavior [16].

Customer Experience Model of B2C E-commerce Logistics Enterprises based on TAM Model

Through the review of literatures, it can be seen factors affecting customer experience of B2C E-Commerce logistics enterprises are website usefulness, website ease of use, transaction costs, customer participation and interaction, and Internet word of mouth. Here website usefulness and website ease of use affect transaction costs, customer participation and interaction, and Internet word of mouth; they also affect customer experience combined with transaction costs, customer participation and interaction, and Internet word-of-mouth, determine customers' purchasing attitudes, and customer purchasing intention finally, and then affect purchasing behavior. This paper establishes customer experience model, as shown in Fig. 1.

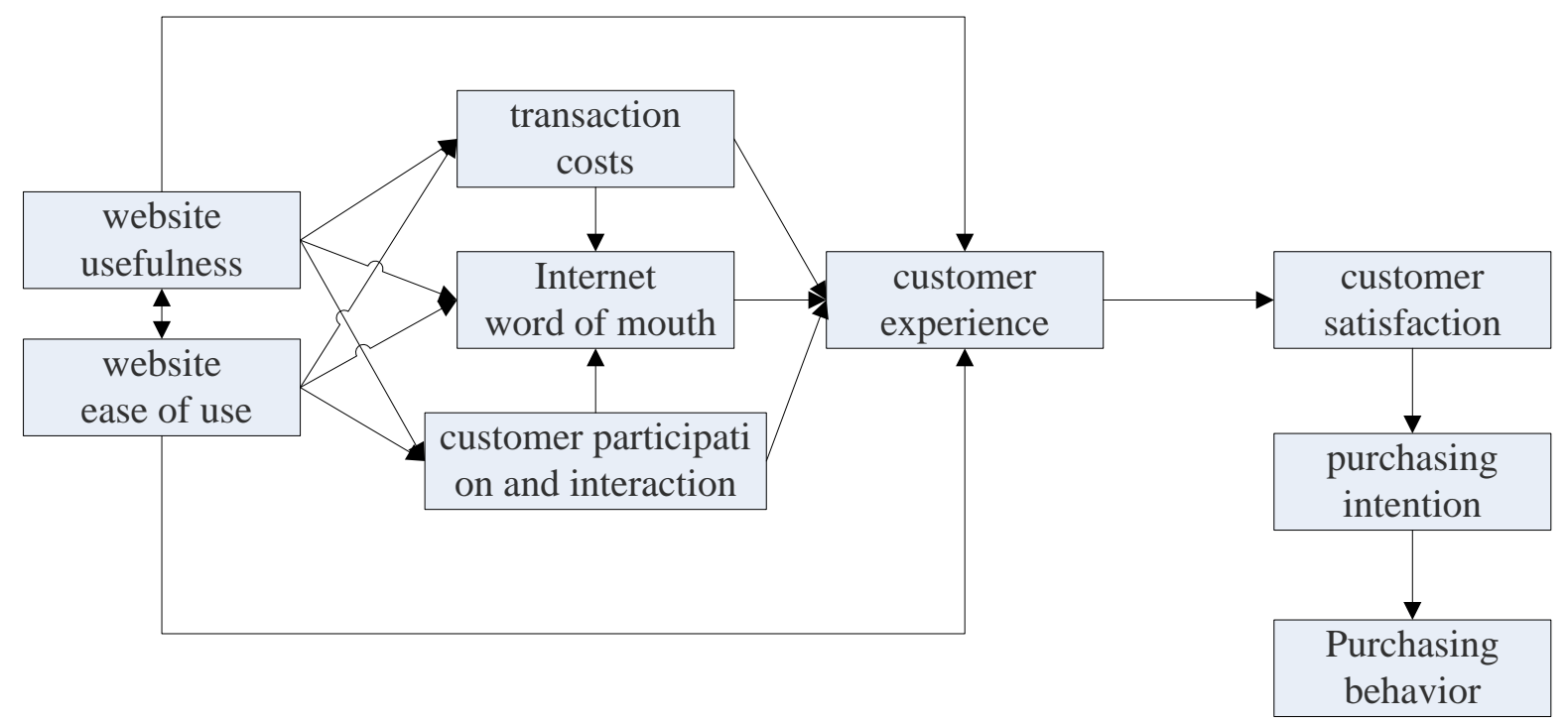

Fig.1. Customer experience model of B2C e-commerce logistics enterprises based on TAM model

The model shows: first, website usefulness is described by product quality, service quality and information quality three variables; website ease of use is described by website function quality, website design quality, the degree of relative convenience three variables. Website usefulness and ease of use influence and restraint each other; website service quality and information quality will affect the degree of customer perception of convenience; meanwhile, website function quality and design quality will also affect customer perception of service quality and information quality.

Second, website usefulness and website ease of use have a direct impact on transaction costs. The time and money it takes to conduct the transaction and risks it takes belong to the scope of transaction costs. Website product quality, service quality and information quality have a direct impact on customer perception of risks. High quality products and services will reduce customers' purchasing cost; meanwhile, the comprehensive and reliable information website provides in order to make customers search and retrieval convenient and answer various problems customers encounter in the purchasing process in time, not only can decrease customer's perceived risk, but also can reduce customer's purchasing cost. Namely, the higher website product quality, service quality and information quality are, the smaller customer's perception of risks in transactions is, and the lower transaction costs are. Website function quality, website design quality and the degree of relative convenience directly affect transaction time. Namely, the more complete website function is, the more beautiful and professional website design is, the more convenient website usage is, the shorter the time customers spend is, the lower transaction costs are .

Third, website usefulness and ease of use directly affect customer participation and interaction. Namely, website product quality, service quality, information quality, website function quality, website design quality and the degree of relative convenience directly affect customer participation 
and interaction. Website product, service, information, function, design and convenience affect customer's perception of experience, and then affect customer participation, including positive or negative participation. Customers' psychological factors and expectations are different, so their feelings of products or services are not the same, and evaluations are not the same. Under B2C e-commerce environment, enterprises transmit information to customers through website product introduction and FAQ and customers can pass information to enterprises through website message board; at the same time, customers and enterprises have two-way communication through e-mail, customer design, and online communities. Enterprises communicate with customers through chat tools and online customer service, reply to customers' questions, provide services for customers such as consulting, price discounts, to increase customer perceived value, and then participate and interact actively.

Fourth, website usefulness and ease of use directly affect Internet word of mouth. Namely, Website product quality, service quality, information quality, website function quality, website design quality and the degree of relative convenience directly affect Internet word of mouth. In an online shopping environment, due to the virtuality of online shopping, customers can not touch products, get products and related information only through enterprise website, understand product performance, quality and other conditions, feel enterprises' service levels through online consultation and communication, form the perception and evaluation of product quality, utility, service and other benefits; meanwhile, website product quality, information quality, website response time when customers raise questions; and the rationality of webpage interface design will have a significant impact on customer perceived value and evaluation. Higher product quality, service quality and information quality, more perfect website function and design, the convenience of website will have positive word of mouth.

Fifth, transaction costs and customer participation and interaction directly affect Internet word of mouth. Transaction costs include not only tangible currency customers pay, but also transaction time and intangible spirit cost, namely perceived risks. In the process of online shopping, the reasonableness of product price and the degree of customer perceived risks will have a significant impact on customer reviews. Reasonable price and lower risk perception will have positive word of mouth. At the same time, customers' active participation and interaction with enterprise websites will make customers evaluate enterprise products and services positively and rationally, and have positive word of mouth.

Sixth, website usefulness, ease of use, transaction cost, customer participation and interaction and Internet word-of-mouth will affect customer experience; customer experience affects customer satisfaction; customer satisfaction affects purchasing intention and leads to purchasing behavior. High quality goods, rich information content, reasonable price and timely services will bring good customer experience; beautiful and practical webpage design, simple, intuitive and clear operating procedures, clear and easily understood website function, accurate product recommendations will increase customer perceived value, and improve customer experience. In the process of customer online shopping, dealing with customer problems fast, completely and reasonably, answering various problems customers encounter in time in the process of before-sale and after-sale service, establishing production and supply information chain with customers, allowing customers to participate in business activities, communicating and interacting with customers with blog, BBS, micro-blog and other social medias, and customers' positive reviews, all will bring great customer experience for customers. Good customer experience makes customer satisfied. Those shopping websites that make customers feel the enjoyment of the spirit and indulge in shopping without stopping can enhance customer satisfaction. Enterprise websites make consumers happy from the sensory and interactive perspective, enhance customer's pleasant shopping mood through good experience, arouse a positive emotional response, and form a sense of belonging, which promote customers to have a more positive attitude to products and services, and enhance customers' sense of satisfaction to shopping websites. Customer satisfaction will enhance customer confidence in purchasing; stimulate consumer purchasing intention, and bring purchasing behavior finally. 


\section{Conclusion}

This paper establishes customer experience model of B2C e-commerce logistics enterprises based on TAM model on the basis of website usefulness, ease of use, transaction costs, customer participation and interaction and Internet word-of-mouth. The five dimensions interact with one another, and have a direct impact on customer experience, and then affect customer satisfaction and purchasing intention. This model can be used to supplement the research theory of customer experience in $\mathrm{B} 2 \mathrm{C}$ e-commerce environment, and help $\mathrm{B} 2 \mathrm{C}$ e-commerce logistics enterprises to understand and predict customer intention in online shopping better. In future studies, we can sum up previous literatures, combine with the model proposed in the paper, develop scales for influencing dimensions of customer experience, and collect data combining with interviews and questionnaire survey. Domestic and foreign scholars in the previous study use structural equation model to conduct empirical research, which is a revelation for validating and improving the model in this paper, and also the focus of future research.

\section{Acknowledgement}

In this paper, the research was sponsored by Beijing Higher Education Young Elite Teacher Project(No.YETP1761).

\section{References}

[1] Hsuan Yu Hsua. Understanding Customer Experiences in Online Blog Environments [J]. International Journal of Information Management, 2011, (31): 510-523.

[2] Madu, Nchristian, Assumptaamad. Dimensions of E-quality [J]. International Journal of Quality and Reliability Management, 2002, (19): 246-258.

[3] Jaeki Songa. Examining Online Consumers' Behavior: A Service-oriented View [J]. International Journal of Information Management, 2012, (32): 221-231.

[4] Shi Lulu, Kang Hongyan. Analysis of key elements of online shopping experience [J]. Manager's Journal, 2013, (3): 277.

[5] Cao Yuanyuan, Zhang Jiantong. E-commerce Customer Experience Evaluation Research Based on Factor Analysis and Synthetic Fuzzy Method [J]. Shanghai Management Science, 2012, 35(2): 34-38.

[6] Li Wei. Research on Different Types of China's Consumer E-commerce Experience [J]. Modern Business, 2013, (28): 71.

[7] Rodiear, Kleines. Customer Participation in Services Production and Delivery [C]. // Teresa A Swartz, Dawn Iacobuee I. Handbook of services marketing and management. California: Sage Publications, 2000, 111-125.

[8] Hsuan Yu Hsua. Understanding Customer Experiences in Online Blog Environments [J]. International Journal of Information Management, 2011, (31): 510-523.

[9] Wang Li. Empirical Study on the Relationship between Internet Based Customer Involvement and New Product Development Performance [J]. Journal of Industrial Engineering and Engineering Management, 200 7, (4): 95-101.

[10] Xue Jun. Research on Online Consumer Behavior from the View of Transaction Costs [J]. Commercial Economy Studies, 200 5, (29): 64-65.

[11] Liu. An Empirical Review on Transaction Cost Approach in Make-or-buy Decision [J]. Advances in Business Intelligence and Financial Engineering, 2008, 943-950. 
[12] Zheng Lifeng. Impact Analysis of Transaction Cost on Purchasing Intention in Electronic Commerce Environment [J]. Wuxi: Jiangnan University, 2009, 15-38.

[13] Fishbein M, Ajzen I. Belief, Attitudes, Intention and Behavior: An Introduction to Theory and Research [M]. Reading, MA: Addison-Wesley, 1975.

[14] Davis FD. Perceived usefulness, perceived ease of use, and user acceptance of information technology [J]. MIS Quarterly, 1989, 13(3): 319-341.

[15] Zhang Nan. Extended Information Technology Initial Acceptance Model and Its Empirical Test [J]. Systems Engineering-Theory \& Practice, 2007, 16 (9): 123-130.

[16] Guo Hongli. The Study of B2C Customer Experience Model Based on Tam Model. Science and Technology [J]. Management Research. 2013, (19): 184-188. 